\title{
Em memória de Anna Politkovskaïa Ou a importância de ser sério
}

\author{
Margareta Sörenson
}

Quantas vezes assisti no teatro a uma representação sobre a violência? Violência na guerra, violência nas famílias, violência nas esquadras da polícia, nas prisões ou em hospitais psiquiátricos, violência na rua, na escola. Violência fruto de racismo, de sexismo, de abuso de poder contra uma parte da sociedade mais desfavorecida, na vida, no mundo. E quantas vezes me confrontei com encenadores e actores sérios e artisticamente ambiciosos que se propunham discutir, protestar e lutar contra a violência, mas acabavam por lutar apaixonadamente contra si próprios em palco? 0 resultado era frequentemente 0 oposto ao que pretendia ser um panfleto contra a violência. Nestas ocasiões, ao contrário do que se pretendia, encontrava-me no teatro perante uma sessão de tortura, opressão e abuso sexual que se aproximava do limite do entretenimento, violência semelhante à das infindáveis séries televisivas e filmes populares.

0 teatro clássico grego não exibia violência em palco. A violência era descrita aos espectadores e em algumas ocasiões sangue teatral e falsas cabeças decapitadas seriam expostos para ilustrar acontecimentos já consumados. As peças violentas de Shakespeare terão sido encenadas mais realisticamente e com efeitos especiais de todos os géneros, como por exemplo têxteis tingidos de vermelho ou fios de lã compridos para simbolizar sangue, espadas, facas

Margareta Sörenson é crítica de teatro e

dança no jornal

Expressen, Suécia, e membro do Conselho

redactorial da

Danstidningen (revista de dança). É também

Vice-Presidente da

AICT e uma das

responsáveis pelos seminários de jovens críticos desta Associação. falsas e pólvora.

Séculos mais tarde, o teatro existe num mundo tão violento como sempre o foi, mesmo se hoje em dia a sociedade moderna, teoricamente, não tolere a violência. Mas só em teoria! Os espectadores de teatro do mundo ocidental estão habituados a uma enorme quantidade de violência em filmes, televisão e jogos de computador: deste modo, como pode o teatro lidar com a violência no palco? Se os criadores do teatro - dramaturgos, encenadores, actores - desejam criar teatro interessante para si e relevante para o público, é imperativo que exponham perspectivas diferentes da vida e dos problemas contemporâneos, quer sejam violentos ou não. Se o teatro como forma de arte pretende ser convincente, sério e lidar com a importância dos temas dos nossos dias, que interessam e preocupam os espectadores de teatro, a violência não poderá ser evitada. No entanto, o modo como esta é exposta é uma outra questão, e, sem dúvida, os criadores de teatro têm de ser livres para realizarem as suas opções estéticas e artísticas.

Por vezes, sugere-se que Sarah Kane é, de certo modo, a culpada por o teatro expor violência em palco de um modo muito directo e brutal. Penso que Kane e outros apenas reagiram ao que era e ainda é um mundo violento, não apenas no sentido físico do termo, mas também psicologicamente, associando-se a uma vida de consumo, histérica e plena de stress. Eu irei discutir alguns exemplos retirados da produção de Lars Norén, um dramaturgo sueco cujas peças são hoje representadas em vários paises europeus e também nos E.U.A. De facto, as suas peças demonstram como um mundo violento pode ser representado de maneiras muito diferentes através do teatro, desafiando intelectualmente e emocionalmente os espectadores. Ainda quando Sarah Kane frequentava a escola, já Lars Norén se havia consagrado como poeta e dramaturgo, essencialmente inspirado por Eugene O'Neill, Harold Pinter e, claro, August Strindberg, que ainda domina vários aspectos do teatro sueco. A produção de Lars Norén (nascido em 1944) é hoje muito vasta, com cerca de setenta peças. 0 seu trabalho é quase frenético e, ao longo da última década, tem frequentemente encenado os seus próprios textos.

As peças de Lars Norén podem ser agrupadas temática e temporalmente. Nos anos setenta e no início dos anos oitenta trabalhou com material autobiográfico em peças como A noite é mãe do dia (Natten är dagens mor), em que a parte central consiste num auto-retrato do autor enquanto jovem adulto lutando com a sua auto-confiança e simultaneamente com o seu desespero, e o seu confronto com um poderoso pai, vítima de alcoolismo e mentiras. Nos anos oitenta e inícios dos anos noventa seguiram-se as conhecidas "Peças de Verão" com um formato mais leve, tratando o tema clássico das famílias burguesas de 


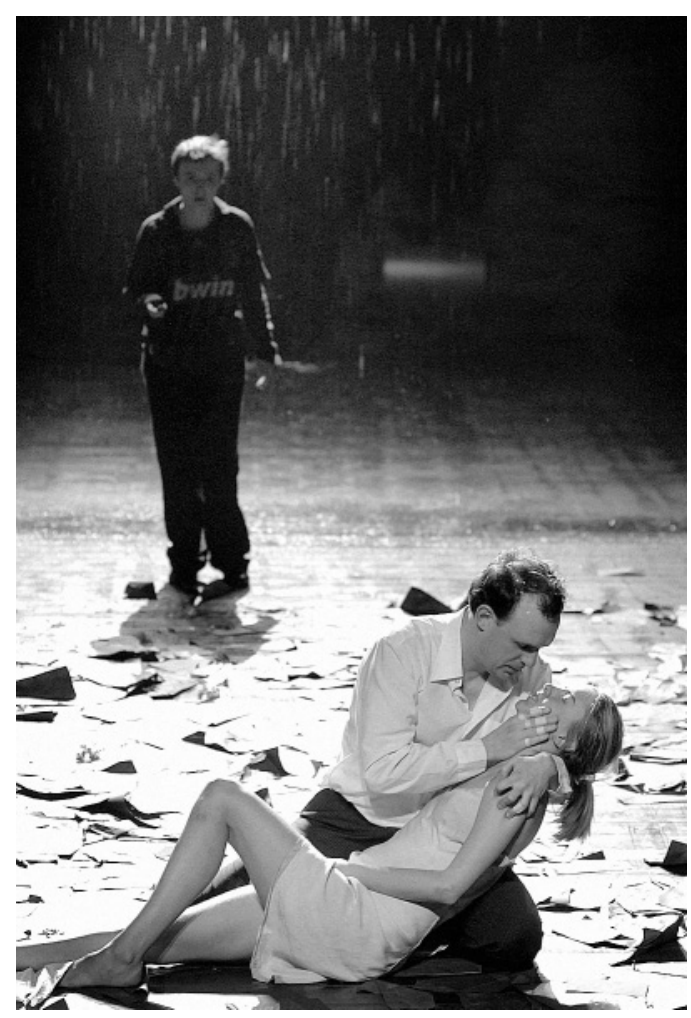

Estocolmo, em simultâneo com a sequência de The Dead Plays (ao todo treze peças, entre as quais se destacam algumas muito encenadas, tais como Romenos

(Romanians), Sangue (Blood), e A clínica (The Clinic)). Nos anos mais próximos da viragem do milénio Norén recupera temas de distopia e resignação, desta vez não colocando a sua pessoa enquanto jovem em foco, mas centrandose em transformações simultaneamente visiveis e invisiveis no mundo ocidental, algumas das quais violentas. Uma perspectiva crítica e religiosa é entrelaçada com uma estrutura fragmentária da peça, testando e revisitando pensamentos básicos da tradição cristã, tais como os valores humanos que todos os individuos partilham: a protecção dos mais desfavorecidos pela pobreza, a idade, a etnicidade ou outras razões.

De 1999 até finais de 2007 Lars Norén dirigiu uma secção do Riksteatern, o Riks Drama, que apresentava maioritariamente peças da sua autoria. Simultaneamente, as suas peças (Norén mantinha-se um dramaturgo muito profícuo) continuaram a ser encenadas noutros teatros, não apenas na Suécia, mas também no estrangeiro. Um tema parcialmente novo emergiu nestes últimos textos, em que a situação actual das crianças é colocada em destaque. As crianças, na familia e na sociedade em geral, estão presas no fogo cruzado entre os valores tradicionais e o comercialismo desenfreado, que atinge a sua expressão máxima com a pornografia e o abuso sexual. As peças Escondido (Fördold), no The Royal Dramatic Theatre, e Em memória de Anna Politkovskaya (À la memoire d'Anna Politkovskaya), no Teatro Nacional, em Bruxelas, as duas estreadas no Outono de 2007, centravam-se precisamente na exploração de crianças.

Várias produções anteriores aproximavam-se do tema da criança como vítima última da sociedade e da civilização. A violência presente nestas peças revela-se extremamente delicada, perturbando o espectador pois o alvo é frágil.

Com efeito, a criança torna-se um símbolo da fragilidade humana em geral, mas o tratamento do tema é extremamente cuidado. Em Frio (Kyla) a história narrada inspira-se num caso real de vida na Suécia. Adolescentes neo-nazis pontapearam até à morte um jovem rapaz com uma aparência "estrangeira". Na realidade, tratava-se do filho de um refugiado sul-americano, mas na peça de Norén a vítima era um adolescente sueco adoptado, nascido na Coreia. 0 rapaz adoptado seria o filho de uma família de classe média, teria terminado a escola secundária, e no momento do ataque estaria a atravessar um parque com uma prenda da avó no bolso: um telemóvel. 0 rapaz é molestado no jardim público, o telemóvel roubado, e dois dos jovens acabam por espancá-lo e pontapeá-lo até à morte. É o próprio Norén quem encena a peça, através
A la mémoire d'Anna Politkovskä̈a, texto e enc. Lars Norén, Teatro Nacional, Bruxelas, 2007 [cortesia Riksteatern]. 

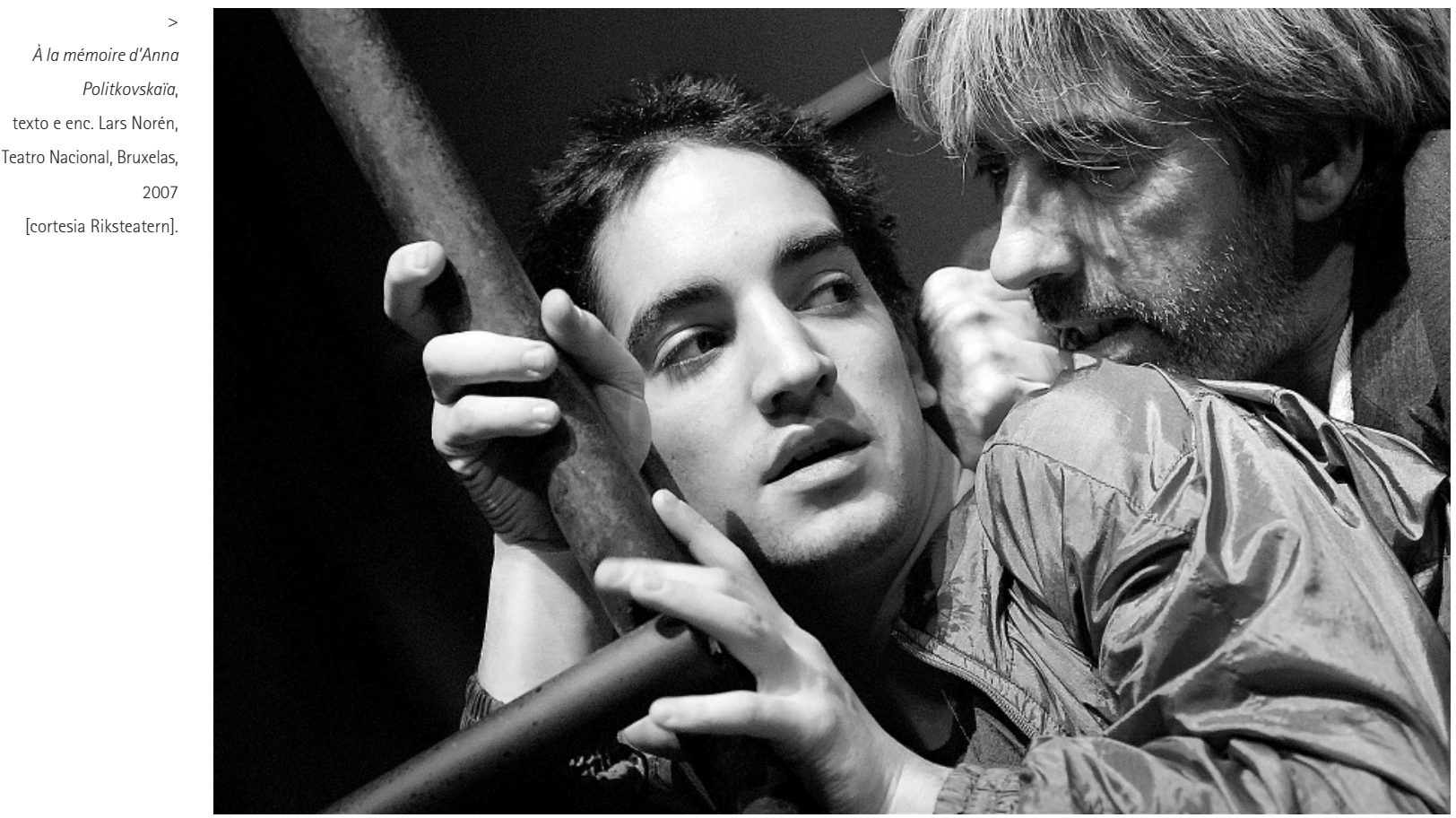

de uma representação seca e sóbria, em que os três jovens actores nunca se chegam a tocar. Na luta final, o encenador opta por uma representação em que os actores batem e pontapeiam o ar, tornando a mesma, de um modo totalmente visivel para o espectador, uma luta sem qualquer contacto, estabelecendo ligeiras associações com as artes marciais e a dança contemporânea. Assim, evitouse uma representação filmica, com violência estonteante e efeitos especiais surrealistas, uma referência imediata para qualquer espectador de teatro contemporâneo.

0 efeito foi mais forte do que numa situação em que se apresenta uma "normal luta fingida de teatro". Sem pensar se esta opção seria dolorosa ou constrangedora para os actores, o público pôde centrar-se no tema, na situação, na violência totalmente irracional e vergonhosa e no racismo.

Em Guerra (Krig), encenado pelo autor numa coprodução franco-suiça, Norén evita novamente utilizar a violência física em palco. Um homem regressa a casa cego no final da guerra. Ele está literalmente cego, não podendo ver que a sua mulher vive com o seu próprio irmão, e que a sua filha mais velha se prostitui para que a familia possa sobreviver. A filha mais nova snifa cola e imita a irmã, mas possui uma ligeira deficiência e é salva do mercado brutal da prostituição. A encenação é sobretudo marcada pelo jogo de olhares silenciosos dos actores que se cruzam um sistema de sinais fora do controlo do homem cego, que conta uma história subtil da vida quotidiana do pósguerra. Simultaneamente, tal como se verifica com frequência nas peças de Norén, esta obra em particular não poderia resultar numa dimensão meramente simbólica: homens que não vêem não se podem aperceber dos efeitos dos horrores da guerra nas mulheres, nas crianças e nos idosos. Agathe Molière, que tem uma formação de palhaço e que tem a capacidade de combinar de um modo fabuloso a tragédia com pormenores cómicos e o comentário, assumiu o papel da filha mais nova. Como sempre numa peça de Norén, há espaço para rir, para o comentário cómico no meio da narração da história mais horrivel.
Nas duas produções de 2007, Norén denuncia o abuso sexual de crianças, e a violência ai envolvida, a partir de duas perspectivas diferentes. A peça Escondido (Fördold) retrata familias suecas de aparência normal, vizinhos numa fileira de casas. Enquanto tudo parece calmo e correcto no exterior, é permitido ao espectador visitar o interior de uma das casas e conhecer um pai desempregado. Ele passa os seus dias - longos e aborrecidos - entretido com o seu computador e a pouco e pouco introduz na sua rotina diária conversas em chats pornográficos, visitas a websites de pornografia infantil, etc. Esta atitude conduz a uma nova perspectiva do pai relativamente à filha adolescente, apenas sugerida - e esboçada - em palco.

Nesta peça o dramaturgo tem como vantagem o facto de o espectador médio de teatro saber exactamente e há muito tempo que os aspectos que se relacionam com a pedofilia, com a pornografia infantil e com a prostituição de crianças não são exclusivos das partes mais pobres do mundo. Através de alusões discretas, dá liberdade total à capacidade intelectual e de imaginação do espectador. No Teatro Dramático Nacional, em Estocolmo, a peça Escondido não foi encenada por Norén, mas a

representação fez justiça ao texto fragmentário e em estilo de esboço, criando um thriller para os espectadores. Será que o pai abusará da filha? Irá agir? 0 que acontecerá?

Na peça Em memória de Anna Politkovskaïa Norén regressa à paisagem aberta e agreste da rua, já explorada em Categoria 3. 1 (Personkrets 3:1), desta vez na Rússia dos dias hoje. Anna Politkovskaïa é apenas uma referência na peça, o seu marido visita-a no cemitério; a acção principal centra-se em três crianças adolescentes que vivem praticamente na rua. Uma dessas crianças, um rapaz, que vive com a mãe solteira, drogada e prostituta, é vendido a homens na rua pelo seu pai biológico. Entre as crianças de rua existe uma certa solidariedade, tornando a vida suportável, mas a vida social desagrega-se sob o efeito das drogas e do álcool, e um dos jovens rapazes acaba por assassinar uma outra criança, uma rapariga cega. 


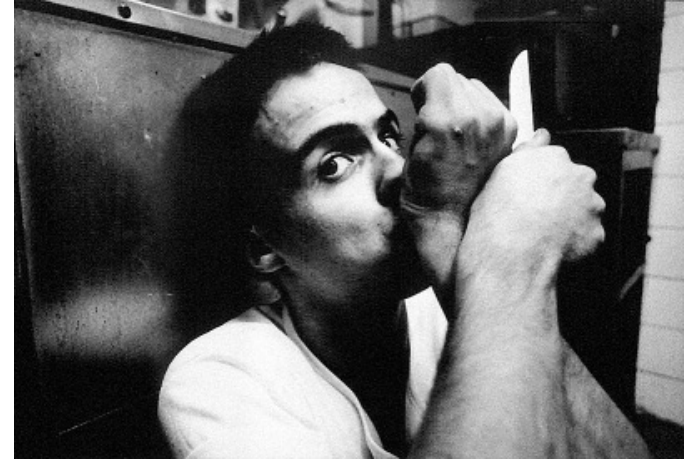

Tal como nas imagens sombrias de uma Bíblia medieval ilustrada, as crianças agem, brincam e sobrevivem em frente de uma imponente catedral. Adultos entoam hinos maravilhosos na igreja enquanto uma criança espanca outra até à morte. Um assistente social internacional exige uma redução no preço da criança pois só se quer "divertir" com ela durante menos de uma hora. As crianças expostas à mais horrivel das explorações humanas não podem confiar nos adultos e nas suas preocupações. Trata-se verdadeiramente de um testemunho triste e desencorajador do nosso tempo.

É penoso de se ver, mas não devido aos efeitos visuais. É penoso porque nos recorda uma realidade. Com efeito, o teatro não é a realidade, e, mesmo quando é representado de forma realista, lembra-nos muitas vezes a distância a que estamos da realidade. Por outro lado, os autores contemporâneos pretendem comentar problemas actuais. Lars Norén é um exemplo evidente de um autor que quer apresentar nas suas peças grandes questões, problemas graves do modo mais delicado e complexo que é possivel. Não se apresentam respostas e há muito pouca esperança. Não seria correcto, no entanto, afirmar que Norén é um pessimista. Existe uma pequena, mas clara torrente de esperança e confiança nas suas peças e nos exemplos mencionados em que a figura principal é a Criança; com efeito, a maioria dos jovens sobrevive, apresentando uma grande ironia, humor e desenvolvendo estratégias para a vida. Os textos de Norén são assim claramente marcados por uma tradição cristã de empatia e humildade.

Na noite de estreia de Em memória de Anna Politkovskaïa, em Bruxelas, sentei-me ao lado de um senhor que bocejou e suspirou durante todo o espectáculo. É realmente necessário mostrar este tipo de peças no teatro? Teremos de ser confrontados com a miséria do mundo? A Bélgica é um país abalado por uma sucessão de escândalos envolvendo o abuso de menores, talvez os espectadores estejam saturados desta temática? Ou será que a questão ainda é para alguns, nova, desagradável e repugnante?

Mas se o teatro, tal como todas as formas de arte, não se leva a sério e tenta ser honesto, qual o seu sentido? As máscaras da comédia e da tragédia, um símbolo ainda presente em muitos teatros, ilustra a tradição teatral. Rir é um direito humano, mas também o é falar seriamente. Enfim, entreter e discutir. Por todo o mundo há violações diárias de direitos humanos, seria estranho se o teatro como forma de arte não lidasse com essa temática. Seria mesmo um erro. Nesta breve apresentação quis evidenciar alguns exemplos de escolhas estéticas que tornam possivel criar um teatro que permita reconsiderar valores morais e sociais. 0 tom poético dos textos, a representação serena e simplesmente bela pode ajudar a desenvolver uma nova atitude e uma nova perspectiva perante factos bem conhecidos e situações da vida actual, sejam eles numa rua de Moscovo ou num subúrbio em Estocolmo. Quando coloca a criança no centro das suas peças, Lars Norén aproxima de todos o elementar da vida, recuperando simultaneamente um símbolo quase romântico. As suas peças demonstram a possibilidade de se ser sério no tratamento da violência, da brutalidade, do desprezo e do ódio, conferindo assim visibilidade à violência num tempo dominado por uma presença esmagadora de violência nos media.

Tradução de Ana Raquel Lourenço Fernandes
A noite é a mãe do dia, de Lars Norén, enc. Solveig Nordlund, CCB e Solveig Nordlund 1998 (Ivo Canelas), fot. Susana Paiva. 